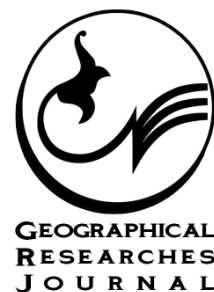

\title{
Correlation of Housing Quality Indices and Perceived Stress in Isfahan Metropolis' Families
}

\section{ART I C L E I N F O}

\section{Article Type}

Original Research

\section{Authors}

Azadeh S.R. ${ }^{1} P h D$,

Mohammadi J. ${ }^{* 1} P h D$,

Neshat Doost H.T. ${ }^{2} P h D$
How to cite this article Azadeh S.R, Mohammadi J, Neshat Doost H.T. Correlation of Housing Quality Indices and Perceived Stress in Isfahan Metropolis' Families. Geographical Researches. 2019;34(3):357-367.
${ }^{1}$ Department of Geography \& Urban Planning, Faculty of Geographical Sciences and Planning, University of Isfahan, Isfahan, Iran ${ }^{2}$ Department of Psychology, Faculty of Educational Sciences and Psychology, University of Isfahan, Isfahan, Iran

\section{*Correspondence}

Address: University of Isfahan, Azadi Square, Isfahan, Iran. Postal code: 8174673441

Phone: +98 (31) 3793308

Fax: +98 (31) 36687396

j.mohammadi@geo.ui.ac.ir

\section{Article History}

Received: March 13, 2019

Accepted: September 23, 2019

ePublished: October 2, 2019

\begin{abstract}
A B S T R A C T
Introduction and Background Based on WHO research, a long range of mental disorders in developing countries and developed countries are related to economic status of a country. Stress is one of the most important mental disorders. The issue, which has been ignored so far, is the impact of the built environment on mental health indices. The main objective of this study is to investigate the relationship between housing quality indices and citizens' mental health in a case study of MoftAbad and Mardavij neighborhoods of Isfahan city.

Methodology The current research is descriptive-analytical and carried out in two district of Isfahan city in 2018. For studying qualitative indices of housing, 8 indices in the internal dimension and 12 others in the external dimension of housing were selected for this study. The dependent variable of the research is perceived stress. To measure stress, the standard perceived stress scale of Cohen et al. (1983) was used which has 14 questions and data were analyzed using Pearson test and also regression analysis.

Findings It was found that the quality of the internal environment in the neighborhoods of MoftAbad and Mardavij, with the intensity of -0.671 and -0.656 respectively, has a significant relationship with perceived stress and the quality of the external environment in relation with perceived stress in MoftAbad and Mardavij neighborhoods is -0.665 and -0.675 respectively. The results of regression analysis showed generally that variables such as interior design and architecture, indoor green space, received natural light, building quality, diversity of green spaces, inappropriate use of color in space, pavement flooring, and the possibility of pedestrianism, the quality of public spaces, environmental cleanliness and environmental security have the most impact on the stress level of urban residents.

Conclusion The quality of house in urban areas can reduce or increase the perceived stress as people live most of their time in houses.
\end{abstract}

Keywords Housing; Housing Quality; Mental Health; Stress; Isfahan Metropolis; Perceived Stress

\section{I T A T I O N L INKS}

[Anderson, et al; 2012] Stress in America...; [Azimi \& Esmaeilzadeh; 2017] Assessing the ...; [Agarwal, et al; 2018] Urbanization urban ...; [Avila-Palencia, et al; 2018] The effects of ...; [Akbari \& Noori; 2014] The status of light ...; [Beil \& Hanes; 2013] The influence of ...; [BehnamiFard \& Habibi; 2018] Evaluating the ...; [Clark, et al; 2008] Witnessing community ...; [Cohen, et al; 1983] A global measure of perceived ...; [Campagna; 2016] Linking crowding ...; [Chong, et al; 2017] A population based survey of ...; [Evans, et al; 2000] Housing quality and ...; [Evans, et al; 2003] Housing and mental health ...; [Frank \& Engelke; 2001] The built environment and ...; [Feizi, et al; 2012] Association of perceived stress ...; [Galea, et al; 2005] Urban built environment ...; [Howden-Chapman; 2004] Housing standards: A ...; [Harvey \& Blackman; 2001] Housing renewal ...; [Hosseini, et al; 2016] The effect of ...; [Izuan, et al; 2018] Neighbourhood ...; [kahlmeier, et al; 2001] Perceived ...; [Kowaltowski, et al; 2006] Quality of life and ...; [Knöll, et al; 2015] Using space syntax ...; [Li \& Liu; 2018] Housing stress and ...; [Lawrence; 2006] Housing and health: ...; [Li, et al; 2012] Several issues about ...; [Lafortezza, et al; 2009] Benefits and ...; [Lee; 2012] Review of the ...; [Lee, et al; 2016] The effect of perceived stress on ...; [Lederbogen, et al; 2013] Urban social stress-risk ...; [Maas, et al; 2009] Morbidity is related ...; [Madebo, et al; 2016] Assessment of perceived ...; [Mirgholami, et al; 2017] The assessment of social ...; [Mubi Brighenti \& Pavoni; 2019] City of unpleasant...; [Mofareh Bonab, et al; 2018] Assessment and ...; [Melis, et al; 2015] The effects of ...; [Nieuwenhuijsen, et al; 2016] Transport and ...; [Pilkington, et al; 2008] Promoting integration ...; [Phillips; 2013] Perceived ...; [Rollings, et al; 2017] Housing and ...; [Rezaei, et al; 2014] Evaluation of satisfaction ...; [Regional Public Health; 2010] Healthy Open Spaces ...; [Sladek, et al; 2016] Perceived stress, coping ...; [Shams \& Gomar; 2016] Evaluation of ...; [Satcher, et al; 2012] Impact of the ...; [Sarmento, et al; 2000] Urban environmental ...; [Shaddel, et al; 2017] Analysis of women's ...; [Srivastava; 2009] Urbanization and ...; [Triguero-Mas, et al; 2017] Natural outdoor ...; [Tabatabaian \& Tamannaee; 2014] Investigation ...; [Taghvaee, et al; 2013] Evaluation of the ...; [World Health Organization; 2017] Depression and ...; [World Health Organization; 2001] The World Health ...; [White; 2014] The Perceived ...; [Zyari, et al; 2018] Analysis of sustainable .... 
شهرنشينى اثرات عمدهاى بر سلامت افراد كذاشته است و بيشتر

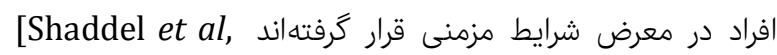

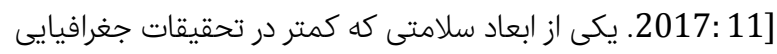

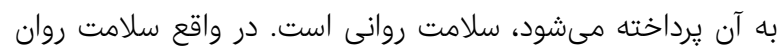

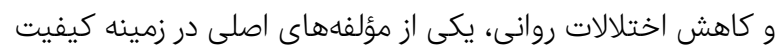

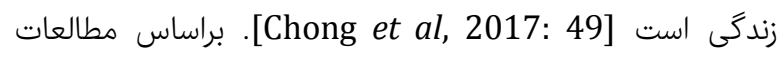

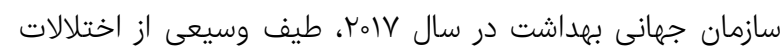

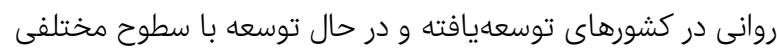

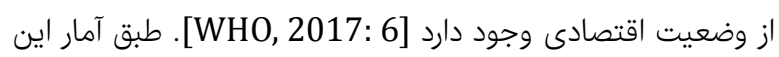

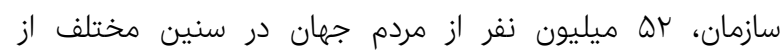

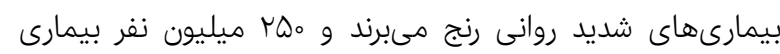

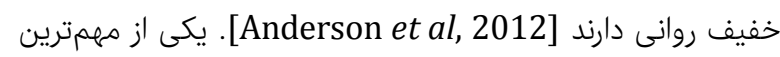

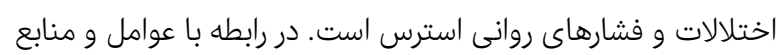

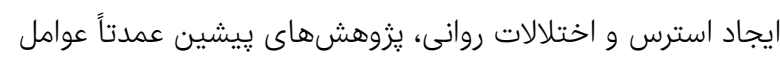

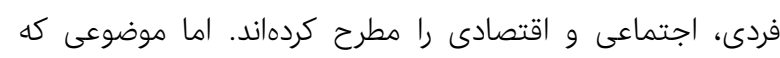

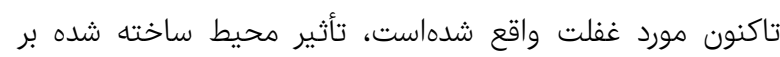

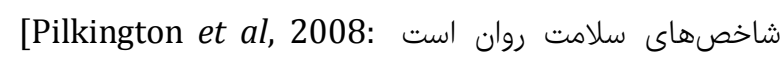
[546. از اين رو امروزه بهبود و ارناء ارتقاء كيفيت كالبدى محيط

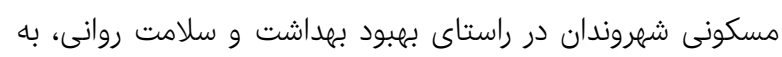

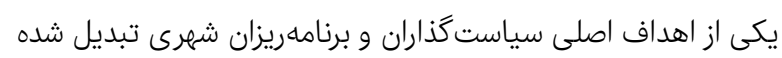

است.

مسكن به عنوان تبلور فضايى و تجسم كالبدى فعاليت سكونتى

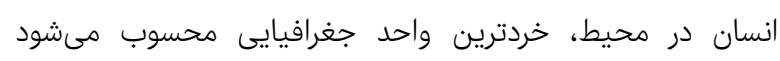

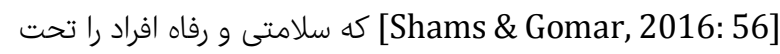

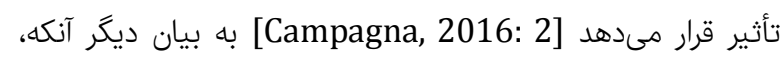

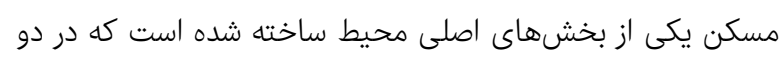

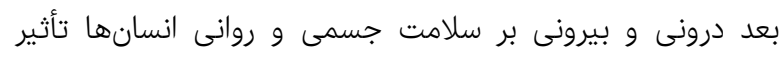

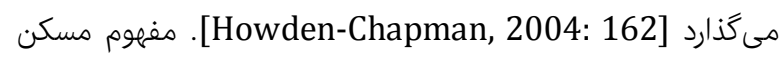

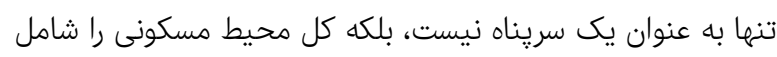
مىشود كه دربركيرنده كليه خدمات و تسهيلات نيات ضرورى مورد نياز

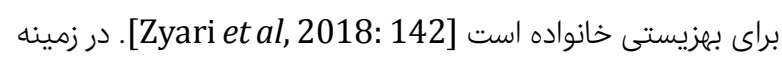

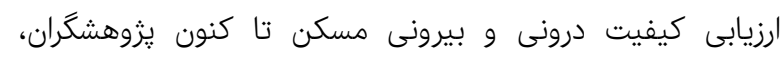

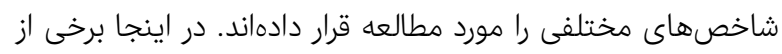

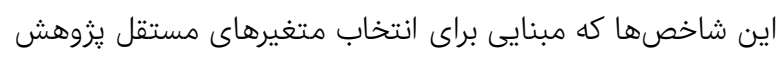

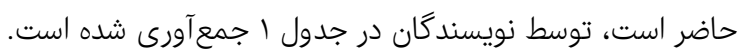

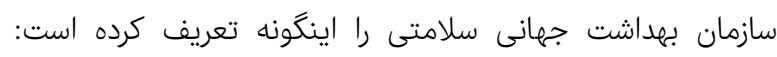

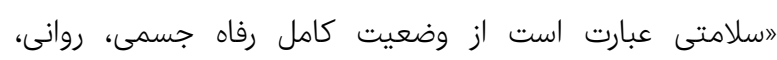

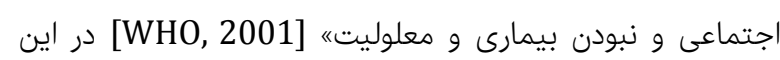

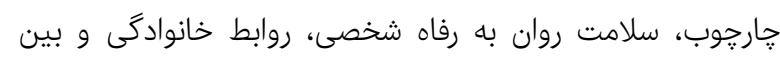

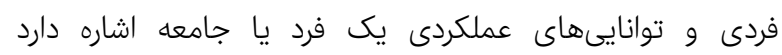

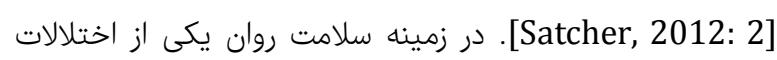

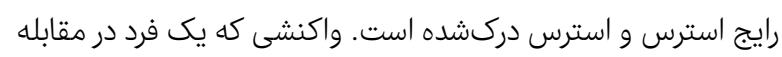

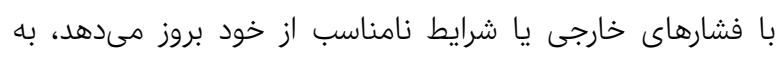

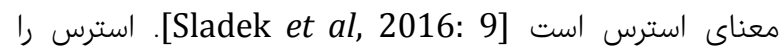

همبستكى شاخصهاى كيفى مسكن و استرس دركشده در خانوارهاى كلانشهر اصفهان سمان

سيدرضا آزاده PhD كروه جغرافيا و برنامهريزى شهرى، دانشكده علوم جغرافيايى و برنامهريزى، دانشكاه اصفهان، اصفهان، ايران

جمال محمدى " PhD

كروه جغرافيا و برنامهريزى شهرى، دانشان دانشده علوم جغرافيايى و برنامهريزى، دانشكاه اصفهان، اصفهان، ايران

حميدطاهر نشاطدوست PhD

كروه روانشناسى، دانشكده علوم تربيتى و روانشناسى، دانشكاه اصفهان، اصفهان، ايران

جكيده

اهداف و زمينهها: براساس مطالعات سازمان بهداشت جهانى طيف وسيعى از

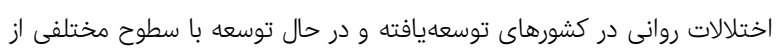

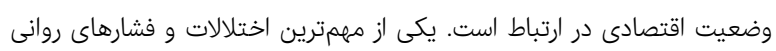

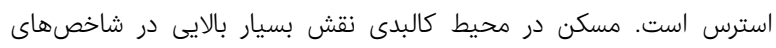

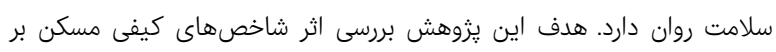

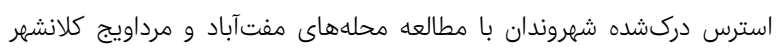

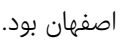

روششناسى: اين يزوهش توصيفى- تحليلى در جامعه خانوارهاى دو محله

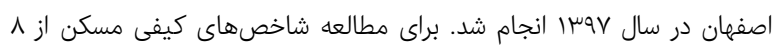

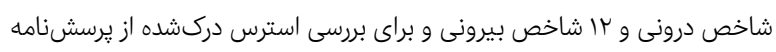

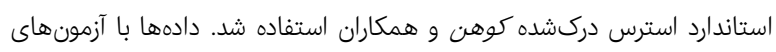

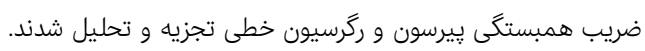

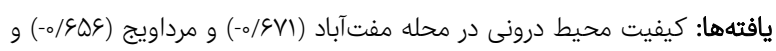

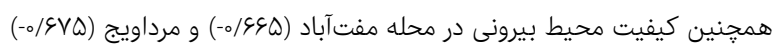

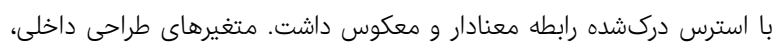

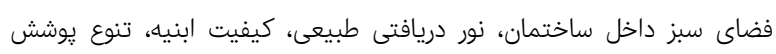

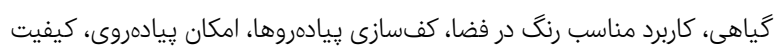

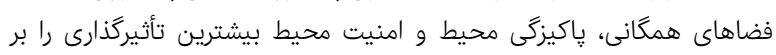

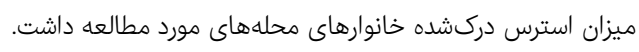

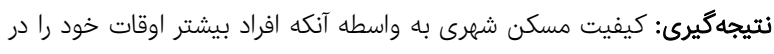

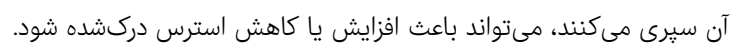

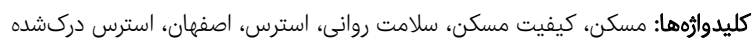

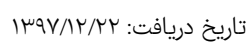

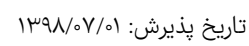

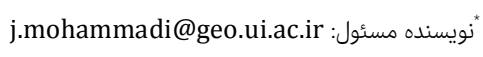

مقدمه

روند شهرنشينى در دنيا از نيمه دوم قرن بيستم به شكل

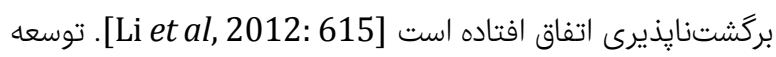

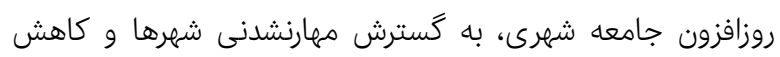

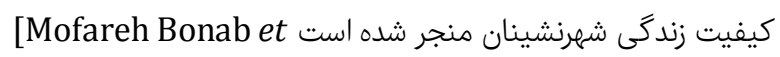

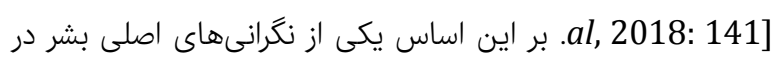

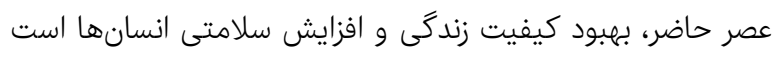

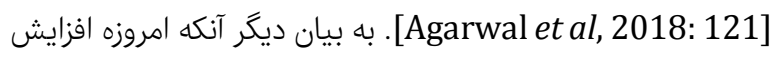




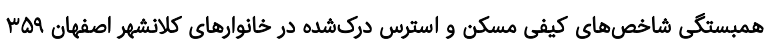

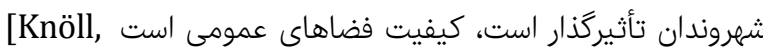
[2015: 247. فضاهاى عمومى فرصت تعاملات اجتماعى را فراهم

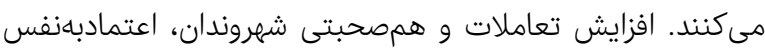

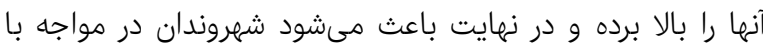

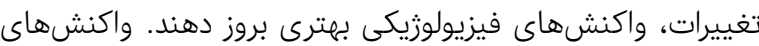
فيزيولوزيكى مناسب باعث كاهش استرس مى شود [RPH, 2010]

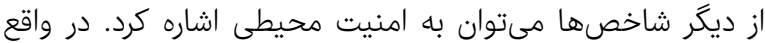

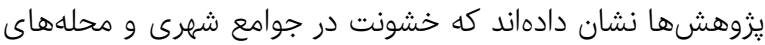
مسكونى، سلامت روان را تهديد مىكند و تأثيرات عميقى بر عملكرد و رفتار روانشناختى دارد [Clark et al, 2008: 22] در رابطه با موضوع يزوهش حاضر، تاكنون در داخل كشور به صورت دان محدود و در خارج از كشور به صورت گسترده مطالعاتى انجام

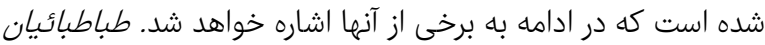

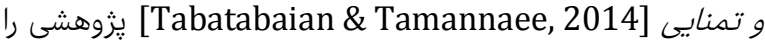
با عنوان ״نقش محيطهاى ساخته شده در سلامت روان" انجام دادهاند. نتايج اين يزوهش حاكى از آن است كه مبانى نظرى موجود

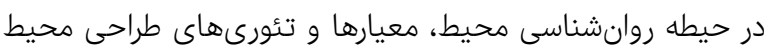

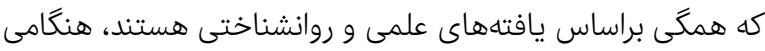
منجر به ارتقاى سلامت جسمى و روانى افراد مى كردد كه مورد كاربرد

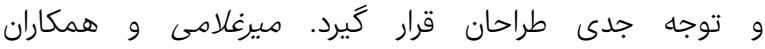
[Mirgholami et al, 2017] در يزوهش خوري خود در محله رشيديه تبريز به اين نتيجه رسيدند كه به ترتيب ساكنين گَونههاى سكونتى تراكم קٍايين، متوسط و بالا با تفاوت معنىدارى، كمتر دجار يريشان

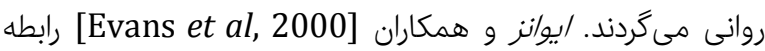
بالقوه كيفيت مسكن و سلامت روان را مورد بررسى قرار دادهاند.

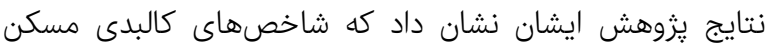
مىتوانند تغييرات اختلالات روانى را يِيشبينى دئنس كنند. بنابراين لازم است تا تحقيقات بيشترى در زمينه رابطه متقابل كيفيت مسكن و وليني [Kahlmeier et al, سلامت روانى انجام شود. كالماير و همكاران [2001 در يزوهش خود به اين نتيجه رسيدند كه شاخصهاى سرواي

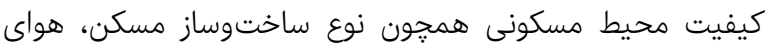

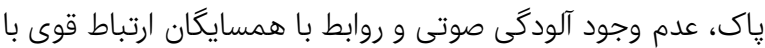

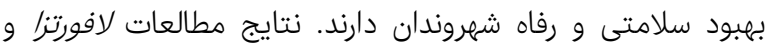
همكاران [Lafortezza et al, 2009] در ايتاليا و بريتانيا نشان داد كه بازديدهاى مكرر و طولانى از فضاهاى سبز، تا حد بسيار زيادى إلاي

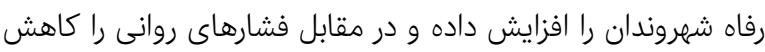
[Mubi Brighenti \& Pavoni, مىدهد. بريجنتى و بإوانى [2019 اين موضوع را مطرح كردند كه فضاهاى شهرى و در واقع

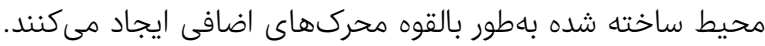

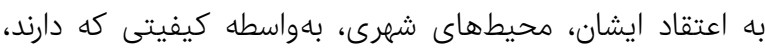

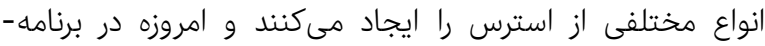
ريزىشهرى نيازمند راهبردهاى سازگار با محيطهاى استراس استرسزا

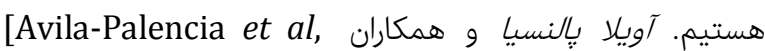

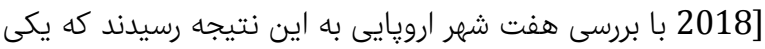

مىتوان به عنوان يك تهديد روانشناختى در نظر گرفت كه در آن فرد يك موقعيت را به عنوان يك تهديد بالقوه مىبيند Madebo]

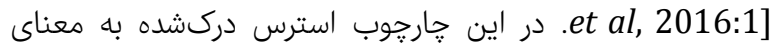
تأثيراتى است كه هيجانات منفى و تهديدات روانشناختى در زندگى دانى

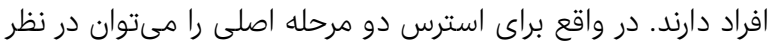

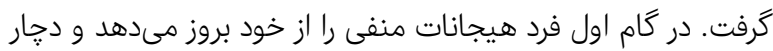

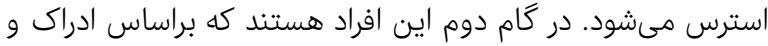

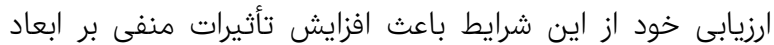

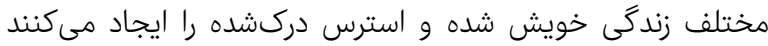

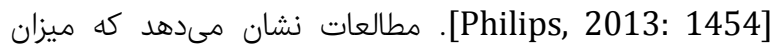
استرس دركشده افراد تحت تأثير عوامل متعددى از قدان قبيل

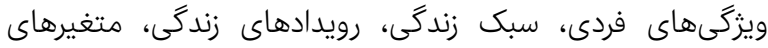

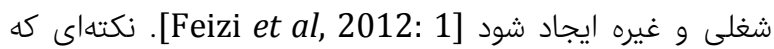

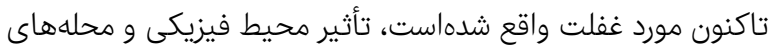

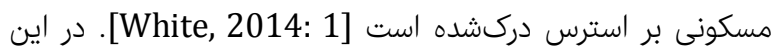
زمينه مىتوان به نظريه لازاروس و فولكان (191K) اشاره كرد، براساس اين نظريه، استرس نه تنها وقايعى است كه منجر به به

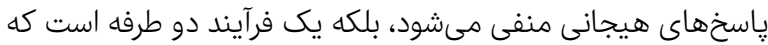

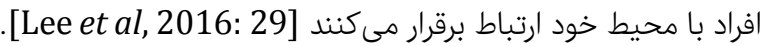
يكى از شاخصهاى كيفى مسكن در بعد محيط درونى، ميزان گرما

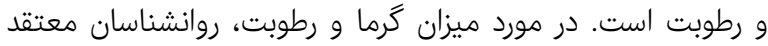

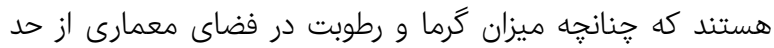
عادى فراتر رود، تحريك، استرس، واكنشهاى منفى و رفتارهاى

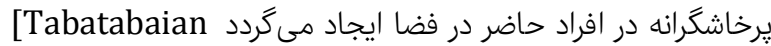

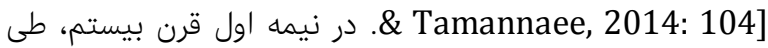
جنگ جهانى اول تا جنگ جهانى دوم، در خانهسازىهايى كه جهت

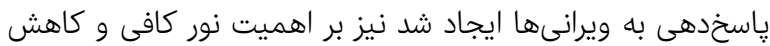

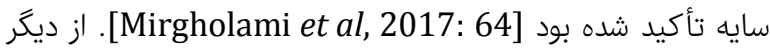
شاخصهاى كيفى، نور و روشنايى است. يكى از عملكردهاى نور در

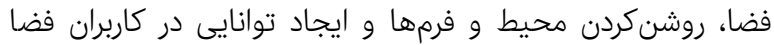

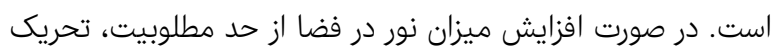

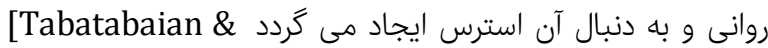

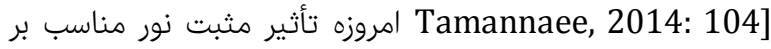
روان، رفتار و خلق و خوى و توليد انرزى مثبت در انسان غيرقابل

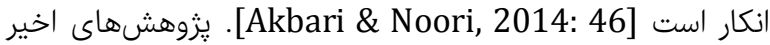
نشان مىدهد كه تماس شهروندان با فضاهاى سبز و پاركها، تأثير بسيار بالايى در كاهش استرس و بهبود سلامت روانى دارد

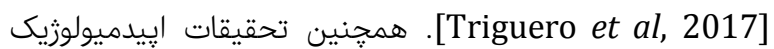
نشان داده است، افرادى كه در نزديكى فضاهاى سبز سكونت دارند،

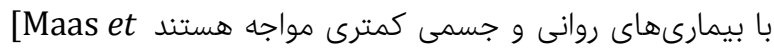

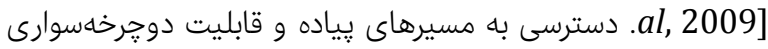

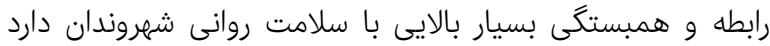
ز . . [Nieuwenhuijsen et al, 2016; Frank, 2016] شاخصهاى ديكر در محيط فيزيكى كه بر وضعيت سلامت روانى 
درونى مسكن را با استرس مهاجران، در با شهر حين بررسى كردهاند.

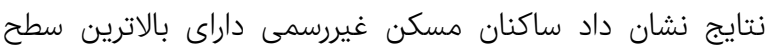

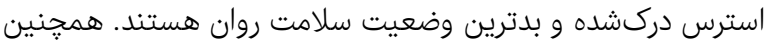
شاخصهاى كيفيت محيط به طور قابل توجهى استرس و سلامت درن

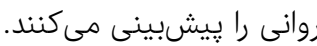

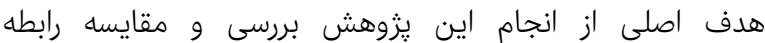
شاخصهاى كيفى مسكن و سلامت روانى شعروندان در محلههاى

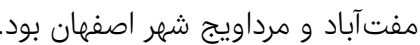

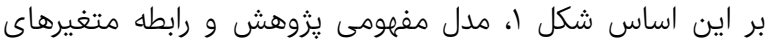
مستقل و وابسته يزوهش را نمايش مى مئهد.
از متغيرهاى اصلى محيط ساخته شده كه در بهبود سلامت روانى

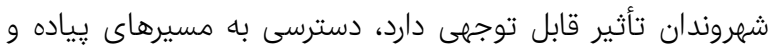

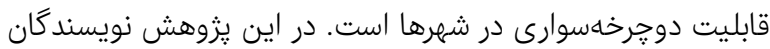

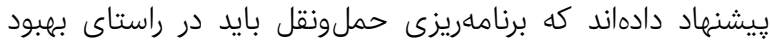

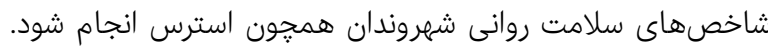

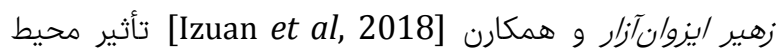
فيزيكى بر سلامت روانى كودكان و نوجوانان را در شهر كوالالاميور

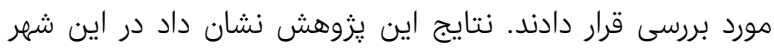

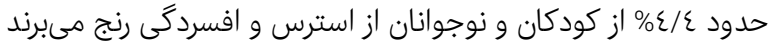

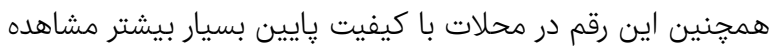

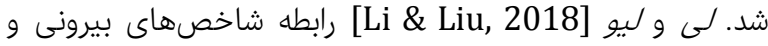

جدول 1) شاخص كيفى مسكن و محيط مسكونى در يزوهش هاى ييشين

\begin{tabular}{|c|c|c|c|}
\hline مأخذ & شاخصهاى مورد مطالعه & 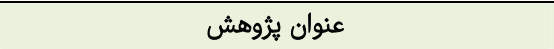 & رديف \\
\hline Sarmento et al, 2000 & 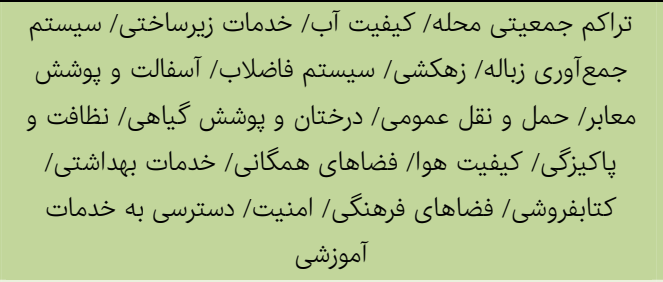 & شاخصهاى كيفيت محيط شهرى & 1 \\
\hline Kowaltowski et al, 2006 & 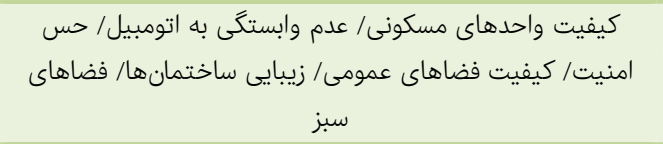 & كيفيت زندگى و توسعه پايدار شهرى & r \\
\hline Taghvaee et al, 2013 & 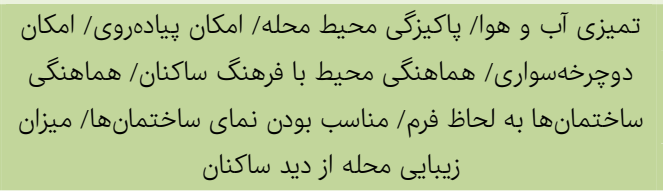 & ارزيابى تأثير كيفيت محيط شهرى بر روابط اجتماعى شهروندان & $\mu$ \\
\hline Rezaei et al, 2014 & استحكام واحد سكونت/ مساحت واحد سكونت/ كيفيت تسهيلات & تحليل رضايتمندى از شاخصهاى كيفيت محيط در & $\varepsilon$ \\
\hline Rollings et al, 2017 & 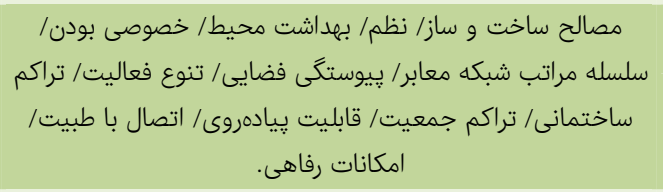 & كيفيت فيزيكى مسكن و محله: سلامتروانى كودكان & 0 \\
\hline $\begin{array}{l}\text { Azimi \& Esmaeilzadeh, } \\
\qquad 2017\end{array}$ & دسترسى به محيط كار/ دسترسى به مراكز خريد/ دسترسى به مراكز & 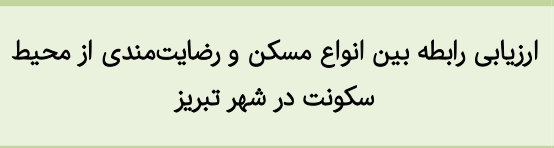 & 7 \\
\hline $\begin{array}{l}\text { BehnamiFard \& Habibi, } \\
2018\end{array}$ & 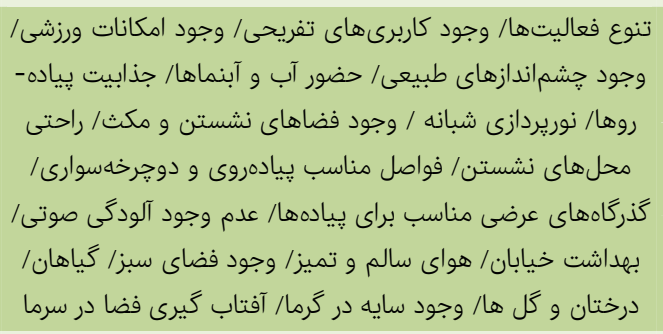 & 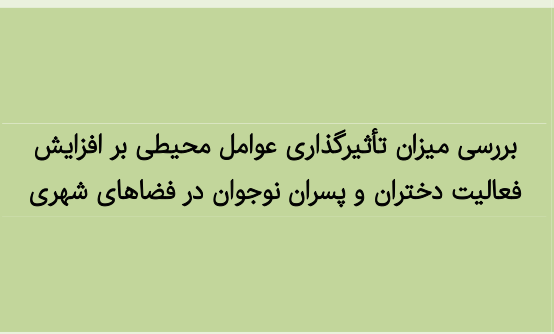 & v \\
\hline Li and liu, 2018 & 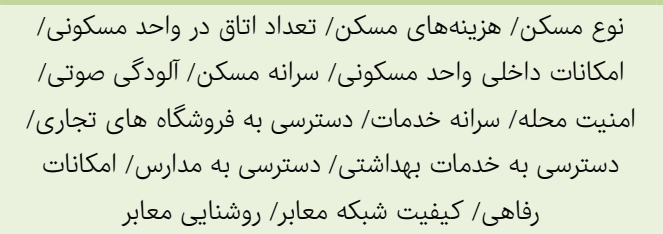 & مسكن، استرس و سلامتروانى در بين مهاجران & $\wedge$ \\
\hline
\end{tabular}




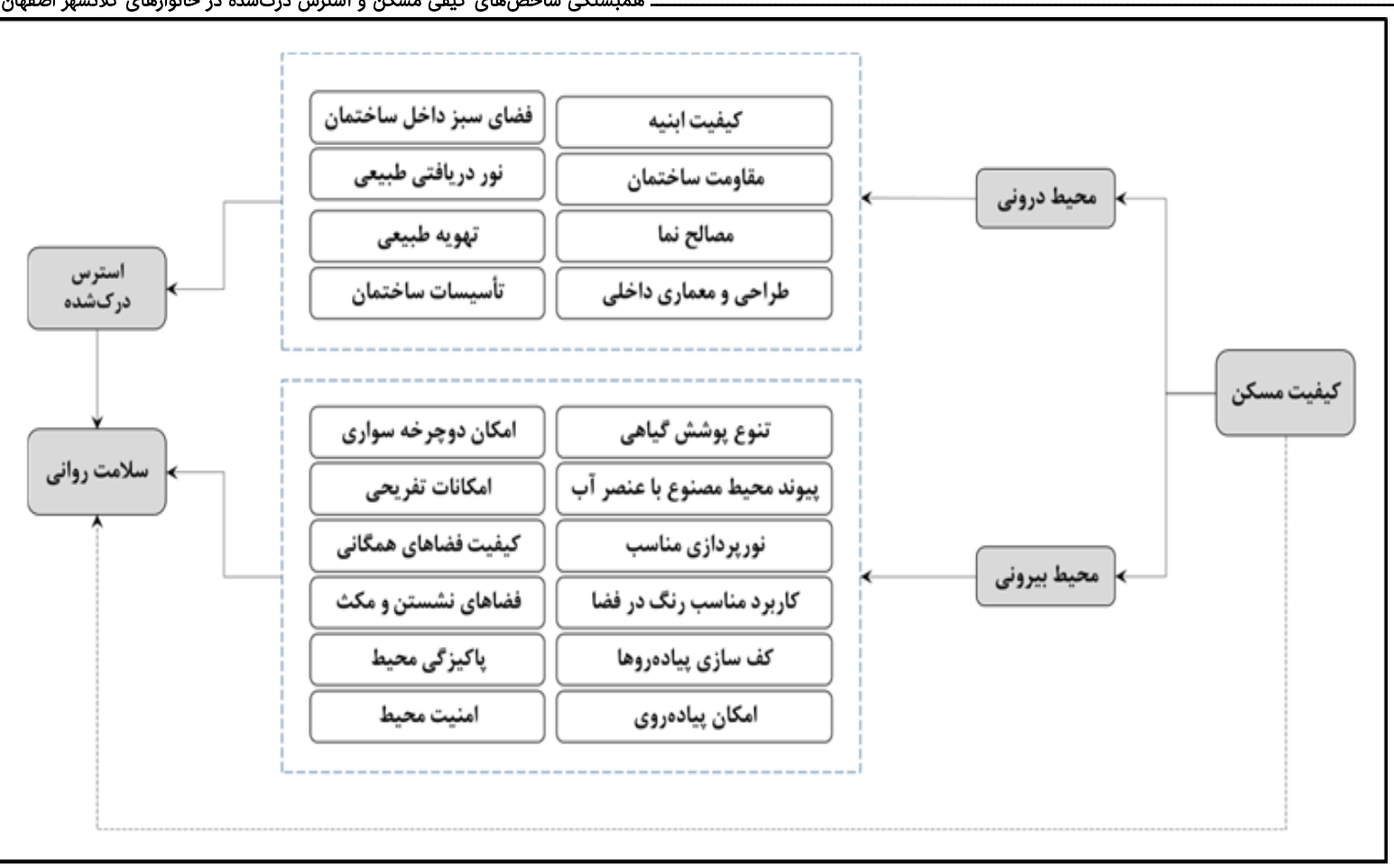

شكل () مدل مفهومى يزوهش

اطمينان فرد نسبت به خويش در حل مشكلات شخصى؛ احساس

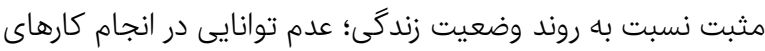

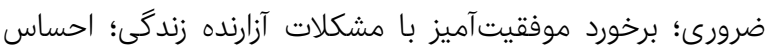

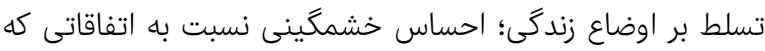

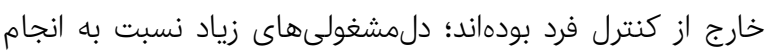
كارهاى ضرورى؛ توانايى در مديريت و استفاده صحيح از زمان؛

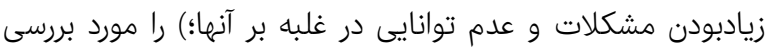

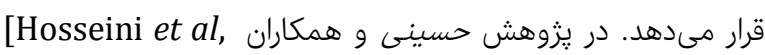

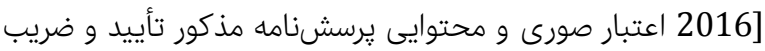

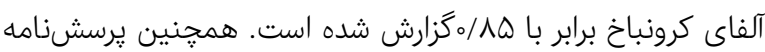

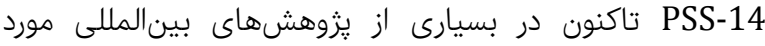

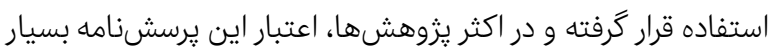

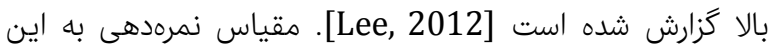

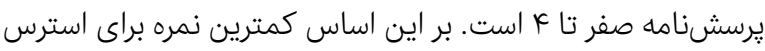
صفر و بيشترين نمره وه است.

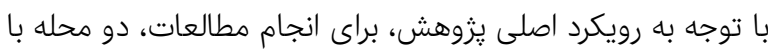

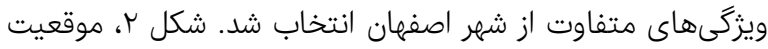

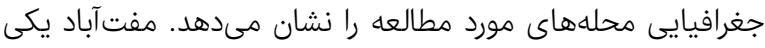

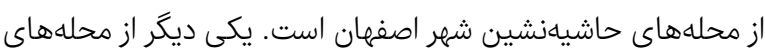
مورد مطالعه، محله مرداويج است. محلهاى امن و آرام كه مردمى از

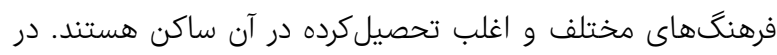

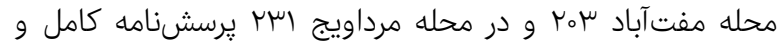
بدون خطا جمع آورى شد. ماتد براى تجزيه و تحليل دادهها، از آزمونهاى ضريب خدري همبستخى ييرسون و ركرسيون خطى استفاده شد.

\section{روش} اين يزوهش توصيفى- تحليلى در جامعه خانوارهاى دو محله

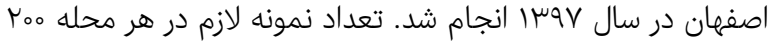

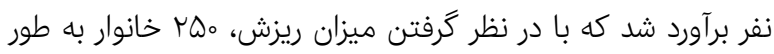

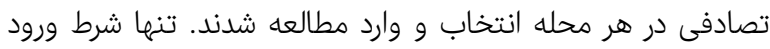

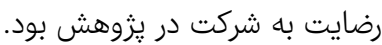
هشت شاخص در بُعد درونى مسكن (كيفيت ابنيه، مقاومت بود

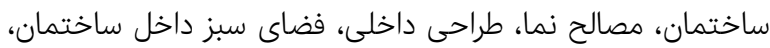

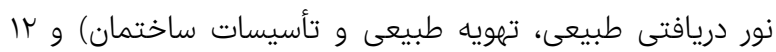

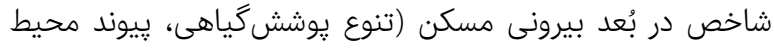

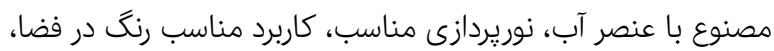

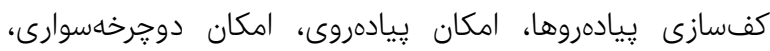

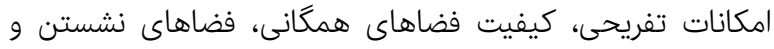

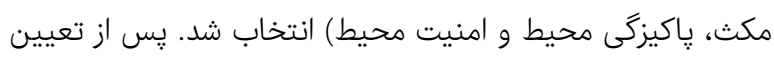
شاخصها، يرسشنامه كيفيت محيطى تنظيم شد. در كام بعدى محيط،

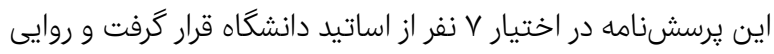

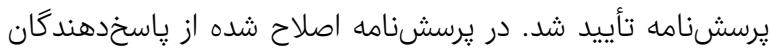
خواسته شد تا كيفيت مسكن و محيط مسكونى خويش رايش را با نمره

$$
\text { صفر تا ع ارزيابى نمايند. }
$$

براى سنجش ميزان استرس دركشده، از يرسشنامه استاندارد استرس دركشده كوهن و همكاران [Cohen et al, 1983]

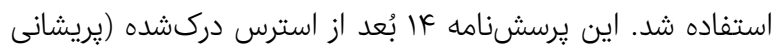

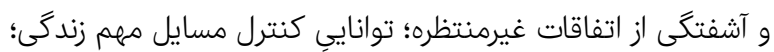
احساس عصبانيت و تحت فشار بودن؛ موفقيت در مقابله با مسايل

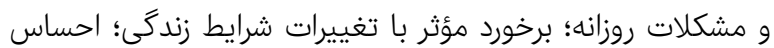


استاندارد استرس دركشده كوهن و همكاران (\%191) ارزيابى شد.

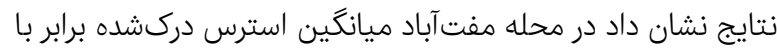

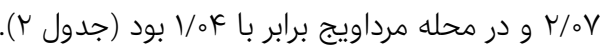

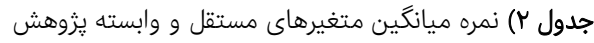

\begin{tabular}{|c|c|c|c|}
\hline 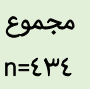 & $\begin{array}{c}\text { محله مرداويج } \\
\text { اسץץ= }\end{array}$ & محله مفت & شاخص \\
\hline & & & محيط درونى \\
\hline$r / 00$ & $\mu / \mu_{0}$ & $1 / \wedge 1$ & كيفيت ابنيه \\
\hline$r / \varepsilon q$ & r/lr & $1 / \mathrm{V} \Lambda$ & مقاومت ساختمان \\
\hline$r / O_{0}$ & $m / 10$ & $1 / V V$ & مصالح نما \\
\hline$r / \varepsilon \Lambda$ & $\mu / \wedge \varepsilon$ & $1 / v^{\mu}$ & طراحى داخلى \\
\hline$r / 7 V$ & 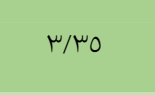 & 1/9。 & سضاخ سبز داخل \\
\hline ( ) & س & $1 / \varepsilon r$ & نور دريافتى طبيعى \\
\hline$r / \mu r$ & $\mu / \diamond$ & $1 / 0$ & تهويه طبيعى \\
\hline$r / \varepsilon q$ & $r / 19$ & $1 / 79$ & تأسيسات ساختمان \\
\hline$r / \varepsilon \wedge$ & $\mu / 17$ & $1 / V_{0}$ & كيفيت محيط درونى \\
\hline$r / \mu q$ & $\mu / \mu r$ & 1/६0 & تنوع يوشش بيرونى \\
\hline$r / r_{0}$ & $r / 9 V$ & $1 / \mu r$ & عنصر آب محيط مصنوع با \\
\hline$r / \varepsilon \varepsilon$ & $\mu / \mu \wedge$ & $1 / \mu \gamma$ & نوريردازى مناسب \\
\hline r & $r / q_{0}$ & $1 / r \varepsilon$ & فضاربرد مناسب رنگ در \\
\hline$r / \mu l$ & $\mu / T V$ & $1 / \pi r$ & كفسازى يِادمروها \\
\hline$r / \mu \mu$ & $\mu / \mu$ & $1 / \mu_{\circ}$ & امكان يِيادروىى \\
\hline$r / \mathrm{TV}$ & $r / 90$ & $1 / \uparrow \Lambda$ & امكان دوجرخهسوارى \\
\hline$r / \mu_{0}$ & $\mu / r q$ & $1 / 1 \Lambda$ & امكانات تفريحى \\
\hline$r / \mu_{0}$ & $\mu / \mu r$ & $1 / 10$ & كيفيت فضاهاى همكانى \\
\hline$r / r \varepsilon$ & r/ro & $1 / 09$ & فضاهاى نشستن و مكث \\
\hline$r / N$ & $r / 99$ & $1 / 1 \varepsilon$ & هاكيزگى محيط \\
\hline$r / \Lambda \Lambda$ & $\mu / \circ 0$ & $1 / r_{0}$ & امنيت محيط \\
\hline r/TO & $m / 10$ & $1 / \Gamma \varepsilon$ & كيفيت محيط بيرونى \\
\hline yor & $1 / \circ \varepsilon$ & $r / \circ V$ & استرس دركشده \\
\hline
\end{tabular}

تحليل همبستگى متغيرهاى مستقل و وابسته

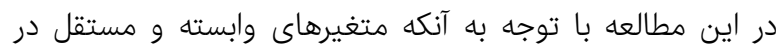

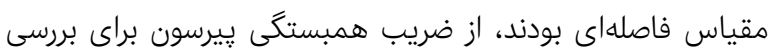

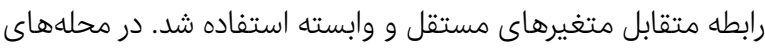

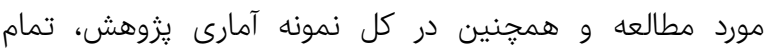
متغيرهاى مستقل با متغير وابسته يزوهش يعنى استرس دركشيده

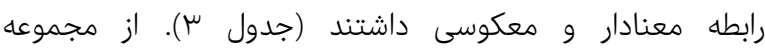

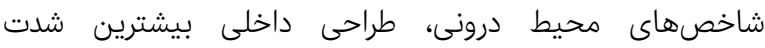

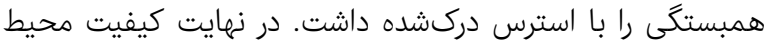

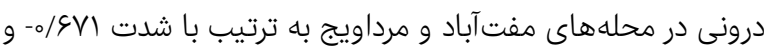

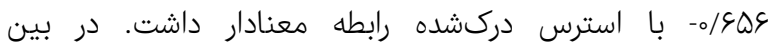
شاخصهاى محيط بيرونى، تنوع يوشش

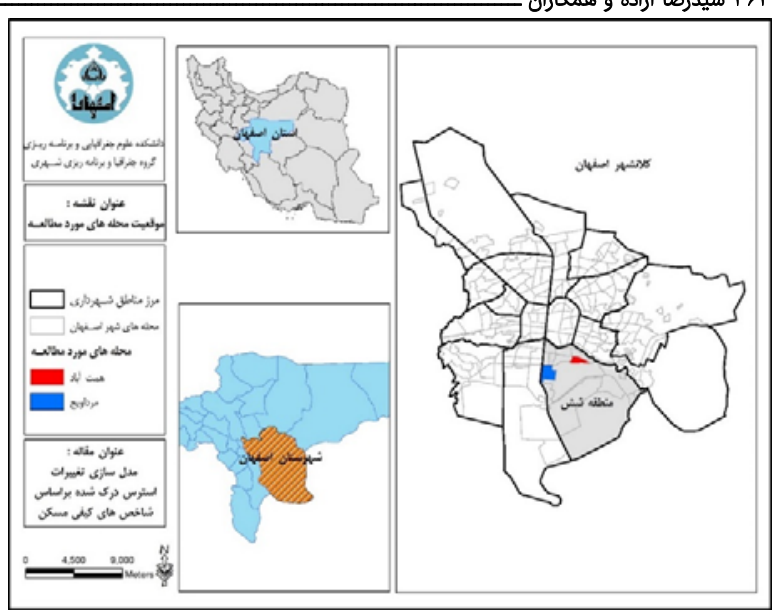

شكل r) نقشه موقعيت جغرافيايى محلههاى مورد مطالعه

\section{يافتهها}

آمار توصيفى وضعيت پاسخدهندكان

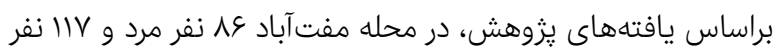
زن در تكميل يرسشنامهها همكارى كردند. در محله مرداويج نيز

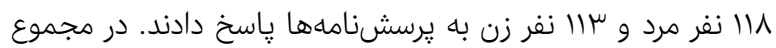

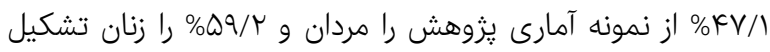

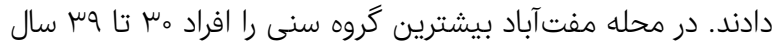

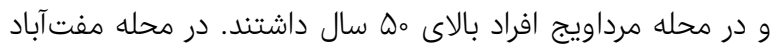

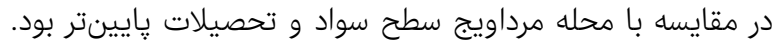

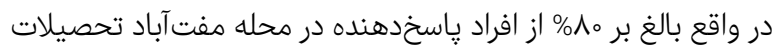

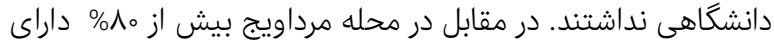

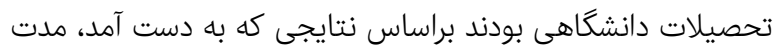

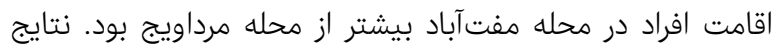
بررسى سطح درآمد حاكى از آن بود كه در محله مفت آباد عمدتاً افراد

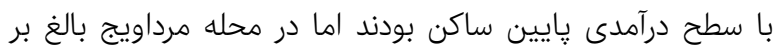

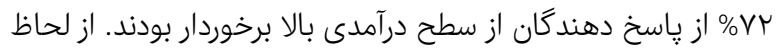

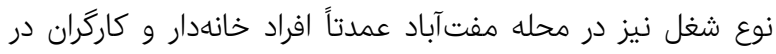
تكميل يرسشنامه همكارى كردند. در محله مرداويج نيز بيشترين كروه شغلى را افراد با شغل آزاد تشكيل دادئد

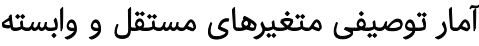

در محله مفتآباد در محيط درونى، شاخص فضيرهاي مستعل وابسته سبز داخل

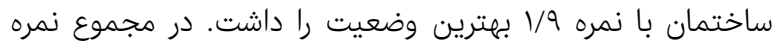

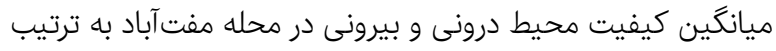

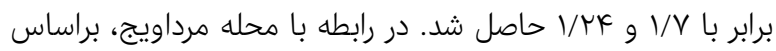

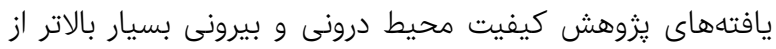

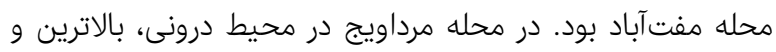

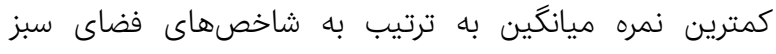

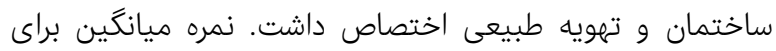

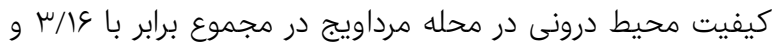

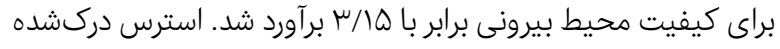

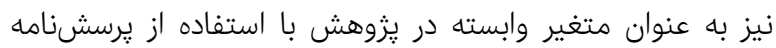


همبستكى شاخصهاى كيفى مسكن و استرس دركشده در خانوارهاى كلانشهر اصفهان سعبر

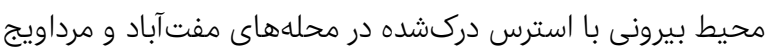
امكان دوجرخهسوارى در محله مرداويج بيشترين شدت همبستگى

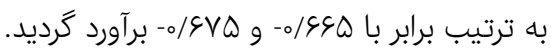

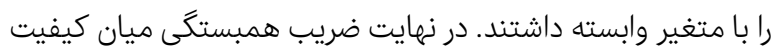

جدول س) خلاصه نتايج تحليل همبستگى شاخصهاى كيفى مسكن و استرس دركشده

\begin{tabular}{|c|c|c|c|c|c|c|c|}
\hline \multicolumn{2}{|c|}{ 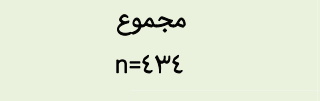 } & \multicolumn{2}{|c|}{ محله مرداويج } & \multicolumn{2}{|c|}{ محله مفت آباد } & \multirow{2}{*}{ شاخص } & \\
\hline همبستگى ضريب & سطح معنىدارى & ضمبيب & معنىدارى & ضريب همبستكى & معنىدارى سطح & & \\
\hline$-0 / V V I$ & $\%$ & 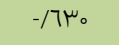 & $\%$ & $-\circ / 071$ & $\%$ & كيفيت ابنيه & \\
\hline$-0 / V \varepsilon r$ & $\%$ & $-0 / 0 \vee \wedge$ & $\%$ & -o/orA & $\%$ & مقاومت ساختمان & \\
\hline$-\circ / \vee \neg \uparrow$ & $\%$ & $-0 / 710$ & $\%$ & $-\circ / 0 \mathrm{VO}$ & $\%$ & مصالح نما & \\
\hline$-0 / \Lambda_{0} \varepsilon$ & $\%$ & $-0 / 774$ & $\%$ & $-0 / 7 \wedge 0$ & $\%$ & طراحى داخلى & \\
\hline$-\circ / V Y \mu$ & $\%$ & $-\circ / \varepsilon O \mu$ & $\%$ & $-0 / 0<9$ & $\%$ & فضاى سبز داخل ساختمان & محيط درونى \\
\hline$-0 / \Lambda_{0} r$ & $\%$ & $-0 / 770$ & $\%$ & $-0 / 709$ & $\%$ & نور دريافتى طبيعى & \\
\hline$-\circ / V \vee \wedge$ & $\%$ & $-0 / 7 r 7$ & $\%$ & $-0 / 701$ & $\%$ & تهويه طبيعى & \\
\hline -o/V91 & $\%$ & - o/70r & $\%$ & $-\circ / 71 Y$ & $\%$ & تأسيسات ساختمان & \\
\hline$-0 / \Lambda \mid V$ & $\%$ & $-0 / 707$ & $\%$ & $-\circ / 7 \mathrm{VI}$ & $\%$ & كيفيت محيط درونى & \\
\hline$-\circ / \Lambda_{\circ} V$ & $\%$ & $-\circ / 7 \mu v$ & $\%$ & $-\circ / 7 \varepsilon 1$ & $\%$ & تنوع بوشش گياهى & \\
\hline$-0 / V \wedge 1$ & $\%$ & $-0 / 71$ & $\%$ & $-0 / 711$ & $\%$ & ييوند محيط مصنوع با عنصر آب & \\
\hline$-\circ / V V \varepsilon$ & $\%$ & $-\circ / 0 \cdot \Lambda$ & $\%$ & $-\circ / 0 \mathrm{~V}$ & $\%$ & نوريردازى مناسب & \\
\hline$-o / V V o$ & $\%$ & $-0 / 700$ & $\%$ & $-0 / 704$ & $\%$ & كاربرد مناسب رنگ در فضا & \\
\hline$-\circ / V V V$ & $\%$ & $-\circ / 000$ & $\%$ & $-0 / 0 \varepsilon \varepsilon$ & $\%$ & كفسازى يِيادمروها & \\
\hline$-\mathrm{o} / \mathrm{\wedge} /$ & $\%$ & $-0 / 7 \varepsilon \wedge$ & $\%$ & $-\circ / 71 Y$ & $\%$ & امكان بِيادهروى & \\
\hline$-0 / \wedge \cdot 0$ & $\%$ & $-0 / 7 \Lambda \varepsilon$ & $\%$ & - - & $\%$ & امكان دوجرخهسوارى & محيط بيرونى \\
\hline$\left.-0 / \Lambda_{0}\right)$ & $\%$ & $-/ 707$ & $\%$ & $-0 / 7_{0} \varepsilon$ & $\%$ & امكانات تفريحى & \\
\hline$-0 / V \wedge 0$ & $\%$ & $-0 / 0 . \Lambda$ & $\%$ & $-\circ / 71 \varepsilon$ & $\%$ & كيفيت فضاهاى همكانى & \\
\hline$-\circ / \vee q \varepsilon$ & $\%$ & $-\circ / 0 \varepsilon 1$ & $\%$ & $-0 / 71 r$ & \%०० & فضاهاى نشستن و مكث & \\
\hline$\left.-0 / \Lambda_{0}\right)$ & $\%$ & $-0 / 741$ & $\%$ & $-\circ / 0 \mu_{0}$ & $\%$ & ياكيزگى محيط & \\
\hline$-\circ / \Lambda \mid \varepsilon$ & $\%$ &.$/ 700$ & $\%$ & $-0 / 719$ & $\%$ & امنيت محيط & \\
\hline$-0 / \Lambda \mu \varepsilon$ & $\%$ & $-0 / 7$ VO & $\%$ & $-0 / 770$ & $\%$ & كيفيت محيط بيرونى & \\
\hline
\end{tabular}

متغير ييشبين تعريف شد. در مدل يِيشنهادى براى محله مرداويج، علاوه بر متغير طراحى داخلى، فضاى سبز داخل ساختمان و ولئن

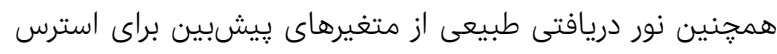

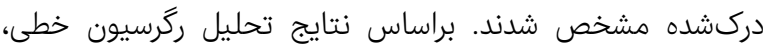

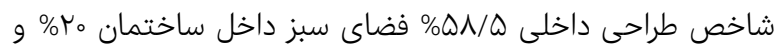

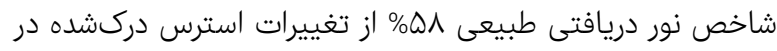
محله مرداويج را ييشبينى كردند. در نهايت با تحليل تمام اطلاعات

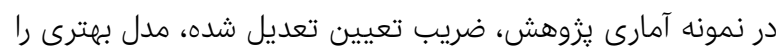

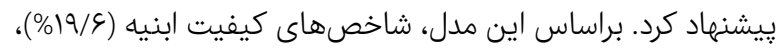

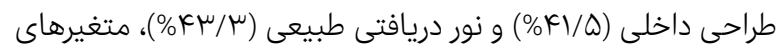
ييشبين براى استرس دركشده در محلههاى شهرى بودند (جدول

در گام دوم، براساس شاخصهاى محيط بيرونى، مدلهاى مربوط

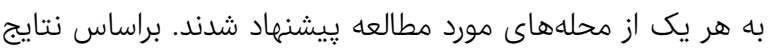

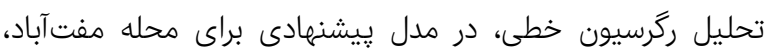

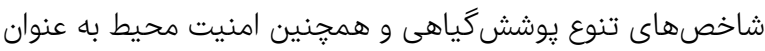

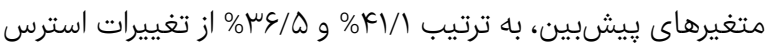
دركشده را تعيين نمودند در مدل ييشنهادى براى محله مرداويج، بهيب،
مدلسازى تغييرات استرس دركشده براساس شاخصهاى كيفى مسكن مدسان در اين مرحله با استفاده از روش رگرسيون خطى، مدلسازى تغييرات استرس دركشده براساس شاخصهاى كيفى مسكن انجام

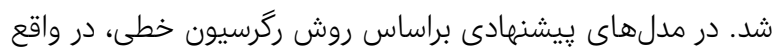

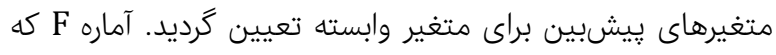
از تحليل ANOVA، استخراج شد، مقبوليت مدل را از نظر آمارى دئ دئير

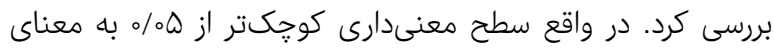

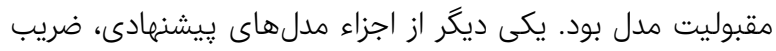

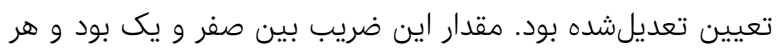

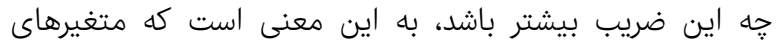

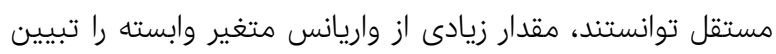
نمايند. در مدلهاى بيشنهادى ضريب تأثير ركرسيونى استانداردشده مئن

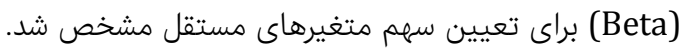

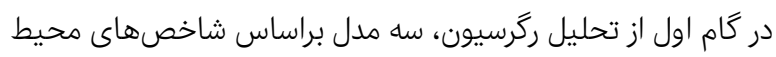

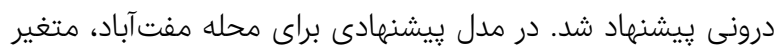

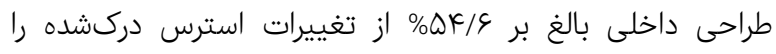
ييشبينى كرد در واقع در محله مفتآباد تنها يكى متغير به عنوان 
در گام سوم، مدلهاى نهايى براساس مجموعه شاخصهاى دو بعد

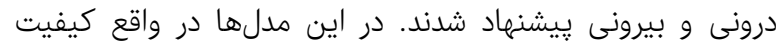

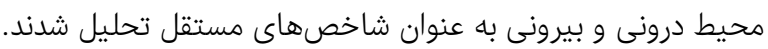

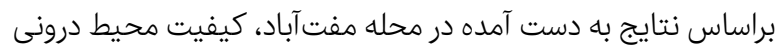

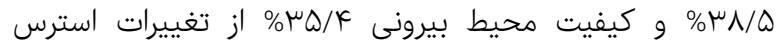
دركشده را ييشبينى كردند در محله مرداويج كيفيت محيط درونى برونى

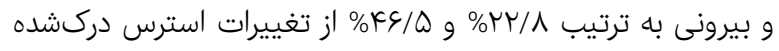

$$
\text { را تعيين نمودند (جدول ه). }
$$

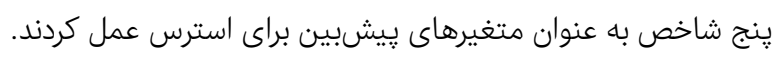

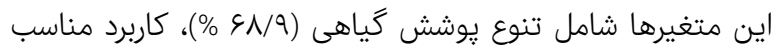
رنگ در فضا (YY/\&)

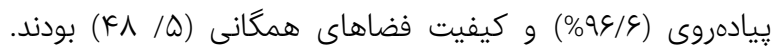

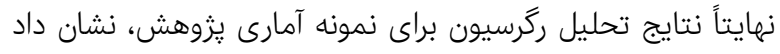

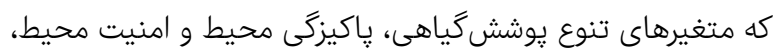

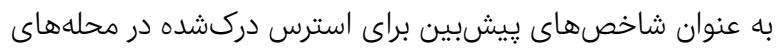

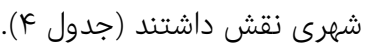

جدول F) مدلسازى تغييرات استرس دركشده براساس شاخصهاى محيط درونى و بيرونى

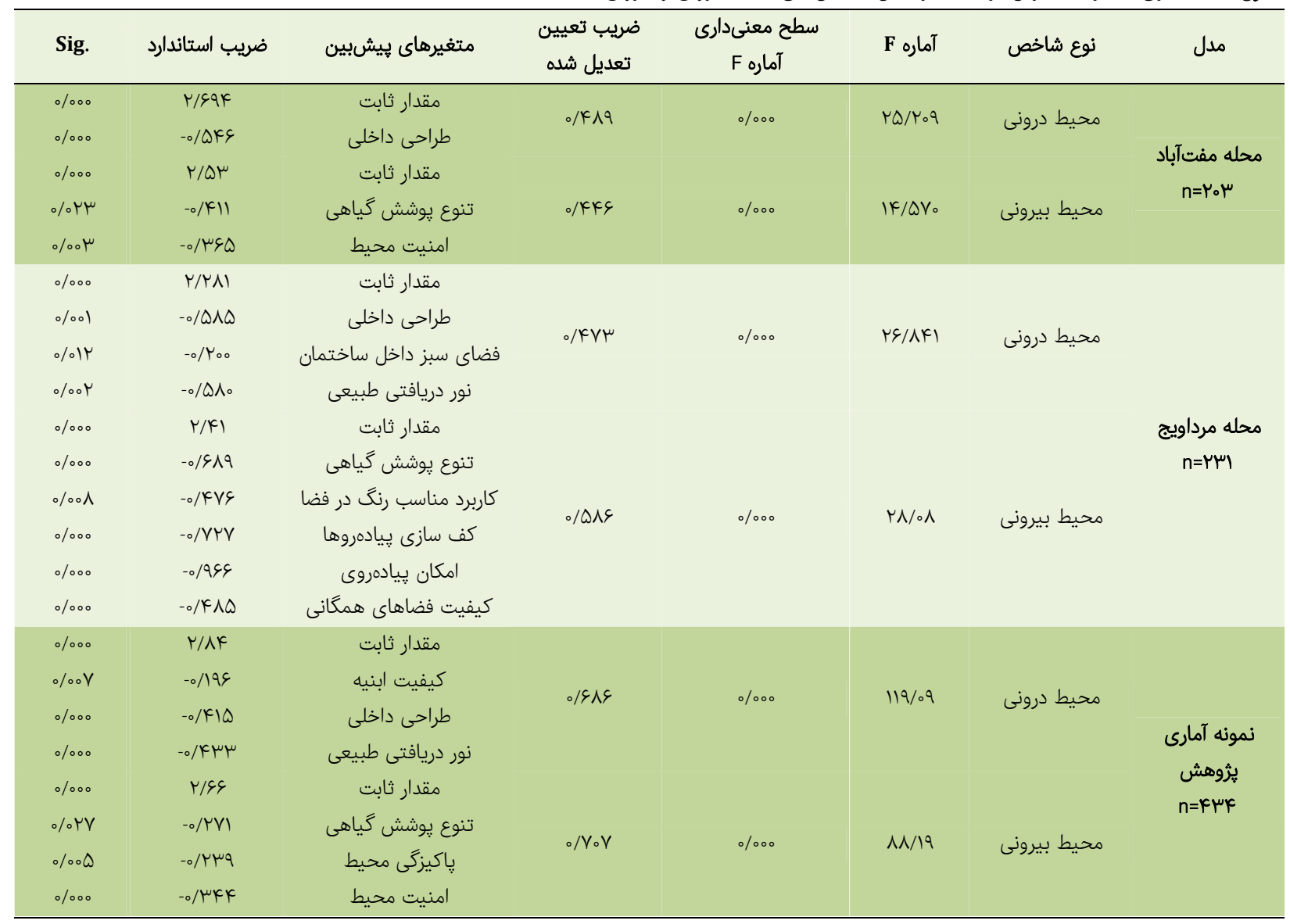

جدول ه) مدلسازى تغييرات استرس دركشده براساس شاخصهاى كيفى مسكن

\begin{tabular}{|c|c|c|c|c|c|c|}
\hline Sig. & ضريب استاندارد & متغيرهاى بيشبين & ضريب تعيين تعديل شده & Fطح معنىدارى آماره F & F آماره F & مدل \\
\hline $\begin{array}{l}\% \% 00 \\
\% 000 \\
\% 000\end{array}$ & $\begin{array}{l}r / V 0 \\
-0 / \mu N \Delta \\
-0 / \mu \Delta K\end{array}$ & كيفيت محيط درونى محيط بيف بيرنى & $\circ / 4 \wedge 9$ & $\%$ & $9 V / \Delta I V$ & محله مفت \\
\hline $\begin{array}{l}\% \% 0 \\
\% \vee \circ \\
\% \circ\end{array}$ & $\begin{array}{l}r / \Lambda 1 \\
-0 / T Y A \\
-0 / K \& D\end{array}$ & كيفت محيط دمدار ثابت درونى & $\circ / \& \Delta \Lambda$ & $\%$ & $৭ \Lambda / \mu \varepsilon \Delta$ & محله مرداويج \\
\hline $\begin{array}{l}\% \% 00 \\
\% 000 \\
\% 000\end{array}$ & $\begin{array}{l}K / \Lambda_{0} \\
-0 / \mu I_{0} \\
-0 / \Delta K V\end{array}$ & كيفت محيط درار ثرونى & $\circ / V_{\circ} \Lambda$ & $\%$ & QYY/OKT & 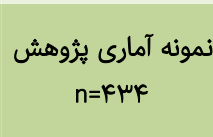 \\
\hline
\end{tabular}


همبستگى شاخصهاى كيفى مسكن و استرس دركشده در خانوارهاى كلانشهر اصفهان هوبر

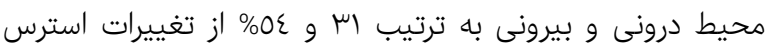
دركشده را ييشبينى مىكنند. تحليلهاى آمارى نشان داد داد كه

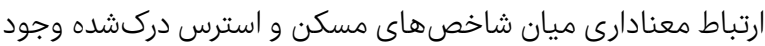

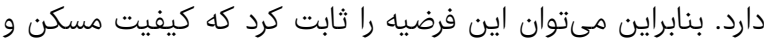
محيطهاى مسكونى، بر ميزان استرس افراد تأثيرگذار است. بِالنسيا

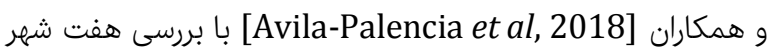
ارويايى به اين نتيجه رسيدند كه دسترسى به مسيرهاى يياده و

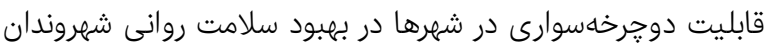

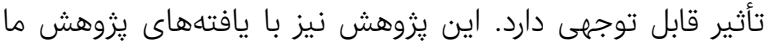

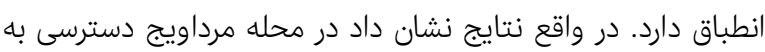

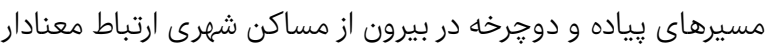
و قابل توجهى با استرس دركشده ونده افراد دارد.

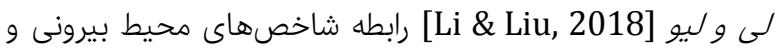

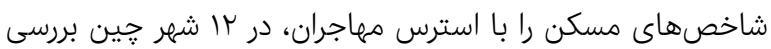

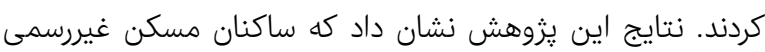
داراى بالاترين سطح استرس دركشده و بدترين وضعيت سلامت درونس

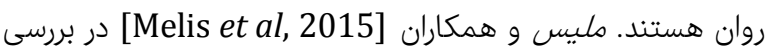

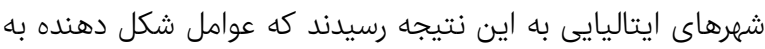

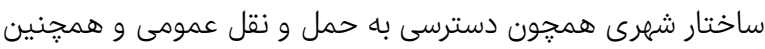
تراكمهاى شهرى تأثير بسيار قوى بر سلامت روانتر دوان دارند. نتايج

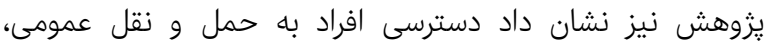

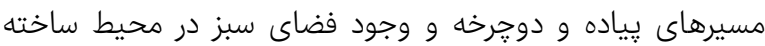

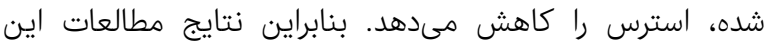

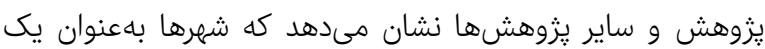

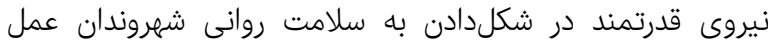

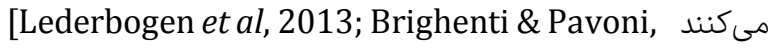
2017; Madebo et al, 2016; Pilkington et al, 2008; و در راستاى كاهش اختلالات روانى نبايد از Galea et al, 2005] محيط ساخته شده و كيفيت مساكن شهرى غافل شد.

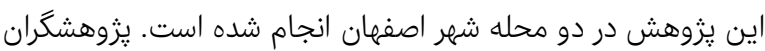

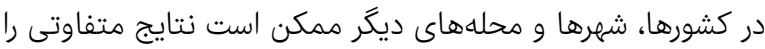

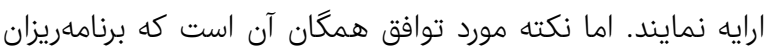

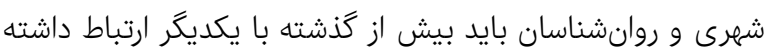

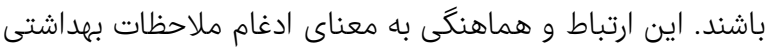

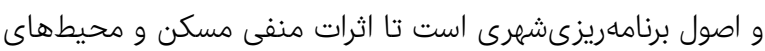
مسكونى بر روح و روان انسان كاهش يابد.

\section{نتيجه}

كيفيت مسكن شهرى به واسطه آنكه، افراد بيشتر اوقات خود را در

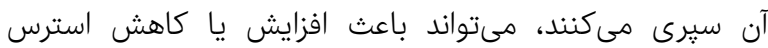

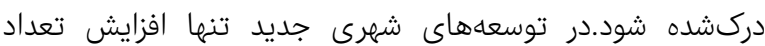

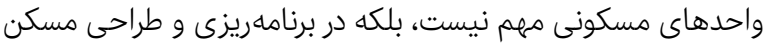

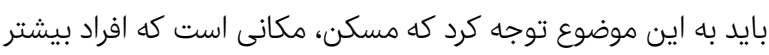

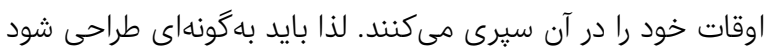

در اين يزوهش رابطه كيفيت مسكن و استرسدركشده در دو محله

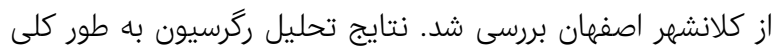

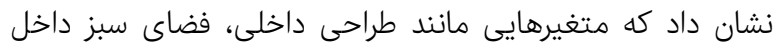

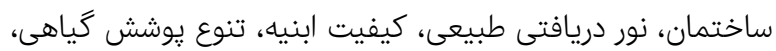

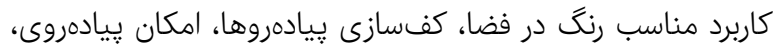

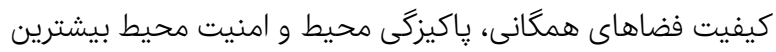
تأثيرگذارى را بر ميزان استرس ساكنان محلههاى شهاى شهرى داريط دارند.

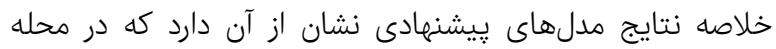

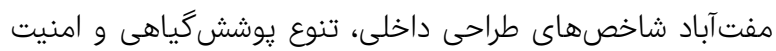

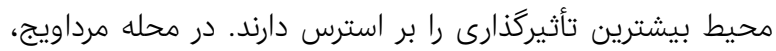
هشت شاخص طراحى داخلى، فضاى سبز داخل ساختمان، نور

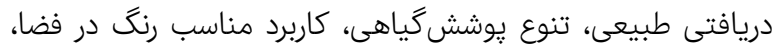

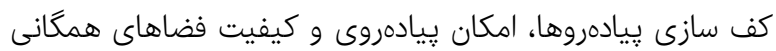

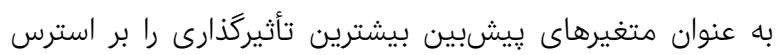

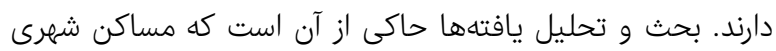

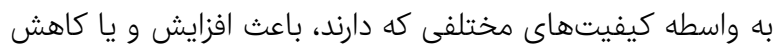
اختلالات روانى مىشوند و مىتوان كَفت مساكن با كيفيت يايين، اختلالات روانى را افزايش مىدهند : Harvey, 2001: 571; Evans et al, 2003: 475; [Srivastava, 2009] سريو/ستاوا .Lawrence, 2006: 540] يزوهشى را با عنوان شهرنشينى و سلامت روانى در كشور هند انجام

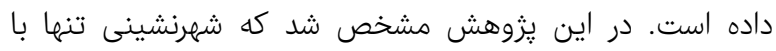

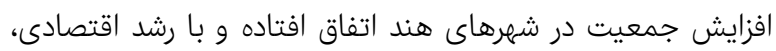
اجتماعى و فرهنكى همراه نبوده است. لذا جمعيت شهرى أفئ عمدتاً با فيا كمبود خدمات و فقر مواجه بوده و همين فقرهاه

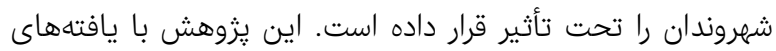

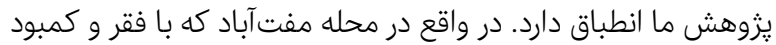

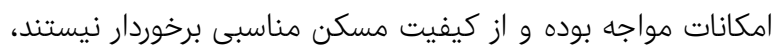
استرس بيشترى بين افراد مشاهده شد. در محله مرداويج كه از

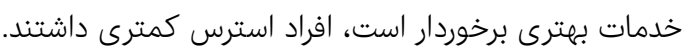

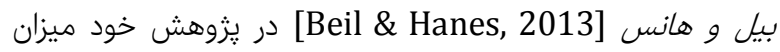

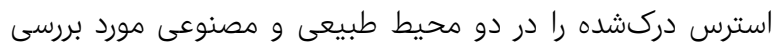

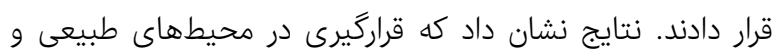

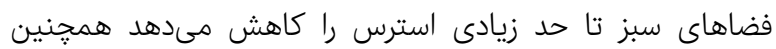

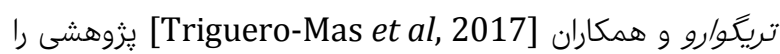
در خصوص ارتباط فضاى سبز بيرونى و سلامت روانى شهروندان

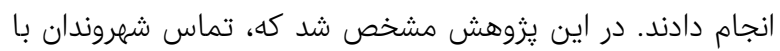
فضاهاى سبز و پاركها، تأثير بسيار بالايى در كاهش استرس درس دارد دارد. در اين يزوهش نيز مشخص شد كه دسترسى به فضاى سبز در محله مرداويج باعث شده است تا افراد استرس كمترى داشته نئه باشند.

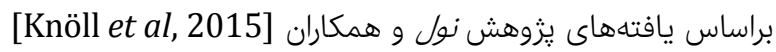

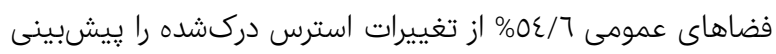

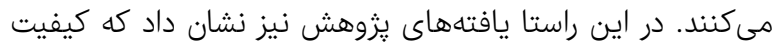


Environmental Psychology. 45:252-266.

Chong SA, Abdin E, Vaingankar J A, Heng D, Sherbourne C, Yap M, et al (2017). A population based survey of mental disorders in Singapore. Ann Acad Med Singapore. 41(2):49-66.

Evans GW, Wells NM, Chan HYE, Saltzman H (2000). Housing quality and mental health. Journal of Consulting and Clinical Psychology. 68(3):526-530.

Evans GW, Wells NM, Moch A (2003). Housing and mental health: A review of the evidenc and a methodological land conceptual critique. Journal of Social Issues. 59(3):475500.

Frank LD, Engelke PO (2001). The built environment and human activity patterns: Exploring the impacts of urban form on public health. Journal of Planning Literature. 16(2):202-218.

Feizi A, Aliyari R, Roohafza H (2012). Association of perceived stress with stressful life events, lifestyle and sociodemographic factors: A large-scale communitybased study using logistic quintile regression. Computational and Mathematical Methods in Medicine. 2012:1-12.

Galea S, Ahern J, Rudenstine S, Wallace Z, Vlahov D (2005). Urban built environment and depression: A multilevel analysis. Journal of Epidemiology \& Community Health. 59(10):822-827.

Howden-Chapman P (2004). Housing standards: A glossary of housing and health. Journal of Epidemiology \& Community Health. 58(3):162-168.

Harvey J, Blackman T (2001). Housing renewal and mental health: A case study. Journal of Mental Health. 10(5):571-583.

Hosseini M, Khoshknab MF, Shahbolaghi FM, Zaheri SM, Soltani P, Khanjani M (2016). The effect of mindfulness program on the perceived stress of family caregivers of elderlies with alzheimer's disease. Iranian Journal of Psychiatric Nursing. 4(3):1-7. [Persian]

Izuan AZ, Azhar SS, Tan MKS, Syed-Sharizman SAR (2018). Neighbourhood influences and its association with the mental health of adolescents in Kuala Lumpur, Malaysia. Asian journal of Psychiatry. 38:35-41.

kahlmeier S, Schindler C, Grize L, Braun-Fahrländer C (2001). Perceived environmental housing quality and wellbeing of movers. Journal of Epidemiology \& Community Health. 55(10):708-715.

Kowaltowski DC, da Silva VG, Pina SA, Labak LC, Ruschel RC, de Carvalho Moreira D (2006). Quality of life and sustainability issues as seen by the population of lowincome housing in the region of Campinas. Brazil. Habitat International. 30(4):1100-1114.

Knöll M, Li Y, Neuheuser K, Rudolph-Cleff A (2015). Using space syntax to analyse stress ratings of open public spaces. In Proceedings of the 10th International Space Syntax Symposium: London, UK.

Li J, Liu, Z (2018). Housing stress and mental health of migrant populations in urban China. Cities. 81:172-179.

Lawrence RJ (2006). Housing and health: Beyond disciplinary confinement. Journal of Urban Health. 83(3): 540-549.

Li J, Liu Q, Sang Y (2012). Several issues about urbanization and urban safety. Procedia engineering. 43:615-621.

Lafortezza R, Carrus G, Sanesi G, Davies C (2009). Benefits and well-being perceived by people visiting green spaces in periods of heat stress. Urban Forestry \& Urban Greening. 8(2):97-108.
كه اثرات منفى بر روح و روان انسان مان نداشته باشد.

تشكر و قدردانى: موردى از سوى نويسندگان گزارش نشده است.

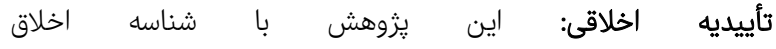
IR.UI.REC.1398.024 در كميته اخلاق دانشكاه اصفهان تصويب إسناسي كرديد. تعارض منافع: موردى از سوى نويسندكان گزارش نشده است.

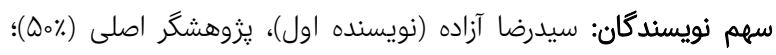

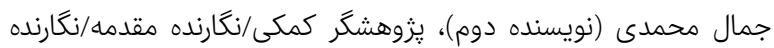

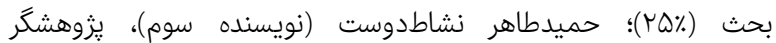
كمكى/روششناس/تحليلكر آمارى (rه\%)

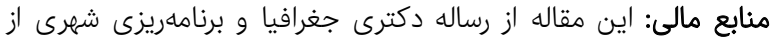

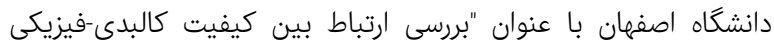

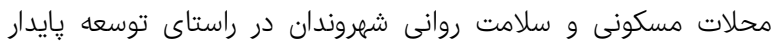

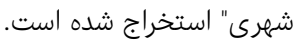

منابع

Anderson NB, Johnson S, Belar C, Breckler S, Nordal K, Ballard D, et al (2012). Stress in America: Our health at risk. Washington, DC: American Psychological Association.

Azimi N, Esmaeilzadeh Y (2017). Assessing the relationship between house types and residential satisfaction in Tabriz, Iran. International Journal of Urban Sciences. 21(2):185-203.

Agarwal S, Satyavada A, Kaushik S, Kumar R (2018). Urbanization urban poverty and health of the urban poor: Status challenges and the way forward. Demography India. 36(1):14

Avila-Palencia I, Panis LI, Dons E, Gaupp-Berghausen M, Raser E, Götschi T, Anaya-Boig E, et al (2018). The effects of transport mode use on self-perceived health, mental health, and social contact measures: A cross sectional and longitudinal study. Environment international. 120:199206.

Akbari S, Noori R (2014). The status of light and color in environmental psychology in designing child-focused treatment spaces case study: Mofid pediatrics hospital. Armanshahr Architecture \& Urban Development. 7(12):45-53. [Persian]

Beil K, Hanes D (2013). The influence of urban natural and built environments on physiological and psychological measures of stress-a pilot study. International Journal of Environmental Research and Public Health. 10(4):12501267.

BehnamiFard F, Habibi M (2018). Evaluating the effectiveness of environmental factors on increasing the activity of adolescent girls and boys in urban spaces case study: Azadi Street of Karaj. Journal of Urban Studies. 7(27):17-26. [Persian]

Clark C, Ryan L, Kawachi I, Canner MJ, Berkman L, Wright R J (2008). Witnessing community violence in residential neighborhoods: A mental health hazard for urban women. Journal of Urban Health. 85(1):22-38.

Cohen S, Kamarck T, Mermelstein R (1983). A global measure of perceived stress. Journal of Health and Social Behavior. 24(4):385-396.

Campagna G (2016). Linking crowding, housing inadequacy and perceived housing stress. Journal of 


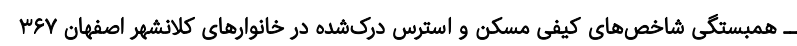
2(1):31-47. [Persian]

Regional Public Health (RPH) (2010). Healthy Open Spaces: A summary of the impact of open spaces on health and wellbeing, Regional Public Health Information Paper March 2010, lower Hutt.

Sladek MR, Doane LD, Luecken L J, Eisenberg N (2016). Perceived stress, coping, and cortisol reactivity in daily life: A study of adolescents during the first year of college. Biological Psychology. 117:8-15.

Shams M, Gomar M (2016). Evaluation of quantitative and qualitative housing in Hamadan province Emphasizing: low-income Families. Regional Planning. 5(20):55-68. [Persian]

Satcher D, Okafor M, Dill LJ (2012). Impact of the built environment on mental and Sexual health: Policyimplications and recommendations. International Scholarly Research Notices. 2012:7

Sarmento R, Zorzal F M B, Serafim A J, Allmenroedr LB (2000). Urban environmental quality indicators. WIT Transactions on Ecology and the Environment. 39:8.

Shaddel L, Rahnama MR, Kharazmi OA (2017). Analysis of women's death spatial autocorrelation and access to urban green areas (Vitamin G) in Mashhad. Geographical Researches Quarterly Journal. 32(3):10-22. [Persian] Srivastava K (2009). Urbanization and mental health. Industrial Psychiatry Journal. 18(2):75-76.

Triguero-Mas, M, Donaire-Gonzalez D, Seto E, Valentín A, Martínez D, Smith G, et al (2017). Natural outdoor environments and mental health: Stress as a possible mechanism. Environmental Research. 159:629-638.

Tabatabaian M, Tamannaee M (2014). Investigation the effect of built environments on psychological health. Armanshahr Architecture and Urban Development. 6(11):101-109. [Persian]

Taghvaee A A, Maroufi S, Pahlavan S (2013). Evaluation of the effects of environmental quality on residents social relations: Aab-Kooh sector in Mashhad city. NaqshejahanBasic studies. New Technologies of Architecture, and Planning. 3(1):43-54. [Persian]

World Health Organization (2017). Depression and other common mental disorders: Global health estimates. Geneva: World Health Organization; Licence: CC BY-NC-SA3.0 IGO.

World Health Organization (2001). The World Health Report 2001: Mental health: new understanding, new hope. World Health Organization. Prees Kit.

White BP (2014). The Perceived Stress Scale for Children: A pilot study in a sample of 153 Children. International Journal of Pediatrics and Child Health. 2(2):45-52.

Zyari S, Farhudi R, Porahmad A, Hataminegad H (2018). Analysis of sustainable housing in Karaj City. Geography and Development Iranian Journal. 16(52):141-156. [Persian]
Lee EH (2012). Review of the psychometric evidence of the perceived stress scale. Asian Nursing Research. 6(4):121-127.

Lee J, Kim E, Wachholtz A (2016). The effect of perceived stress on life satisfaction: The mediating effect of selfefficacy. Chongsonyonhak Yongu. 23(10):29-47.

Lederbogen F, Haddad L, Meyer-Lindenberg A (2013). Urban social stress-risk factor for mental disorders. The case of schizophrenia. Environmental Pollution.183:2-6. Maas J, Verheij RA, de Vries S, Spreeuwenberg P, Schellevis F G, Groenewegen P P (2009). Morbidity is related to a green living environment. Journal of Epidemiology \& Community Health. 63(12):967-973.

Madebo W E, Yosef T T, Tesfaye M S (2016). Assessment of perceived stress level and associated factors among health care students at Debre Birehane University, North Shoa Zone of Amgara Region, Ethiopia. HCCR. 4(2):1-9.

Mirgholami M, Gharehbaglou M, nowzamani N (2017). The assessment of social and physical dimensions of Neighborhood environment on residents' mental health and Wellbeing case study: Roshdiyeh Neighborhood of Tabriz. Honar-Ha-Ye-Ziba. 22(2):63-74. [Persian]

Mubi Brighenti A, Pavoni A (2019). City of unpleasant feelings. Stress, comfort and animosity in urban life. Social \& Cultural Geography. 20(2):137-156.

Mofareh Bonab M, Majnouni Toutakhane A, Soleimani AR, Aftab A (2018). Assessment and analysis of sustainability status in metropolises case study: All ten regions of Tabriz. Geographical Researches Quarterly Journal. 33(1):140-157. [Persian]

Melis G, Gelormino E, Marra G, Ferracin E, Costa G (2015). The effects of the urban built environment on mental health: A cohort study in a large northern Italian city. International Journal of Environmental Research and Public Health. 12(11):14898-14915.

Nieuwenhuijsen M J, Khreis H, Verlinghieri E, Rojas-Rueda D (2016). Transport and health: A marriage of convenience or an absolute necessity. Environment International. 88:150-152.

Pilkington P, Grant M, Orme J (2008). Promoting integration of the health and built environment agendas through a workforce development initiative. Public Health. 122(6):545-551.

Phillips AC (2013). Perceived stress. Encyclopedia of Behavioral Medicine. New York, NY: Springer.

Rollings KA, Wells NM, Evans GW, Bednarz A, Yang Y (2017). Housing and neighborhood physical quality: Children's mental health and motivation. Journal of Environmental Psychology. 50:17-23.

Rezaei MR, Moazzen S, Nafar N (2014). Evaluation of satisfaction rate the urban environmental quality indicators satisfaction rate in new cities case study: the new city Parand. Geographical Urban Planning Research. 